\title{
Life Cycle Assessment of Household Water Tanks-A Study of LLDPE, Mild Steel and RCC Tanks
}

\author{
Kunal N. Shah, Nanik S. Varandani, Monika Panchani \\ Environment \& Energy Efficiency Research Wing (E\&EERW), Gujarat Energy Research and \\ Management Institute (GERMI), Gandhinagar, India \\ Email: kunal.s@germi.res.in
}

Received 16 January 2016; accepted 22 April 2016; published 25 April 2016

Copyright (C 2016 by authors and Scientific Research Publishing Inc.

This work is licensed under the Creative Commons Attribution International License (CC BY). http://creativecommons.org/licenses/by/4.0/

(C) (1) Open Access

\section{Abstract}

A case of household water tanks, $1000 \mathrm{~L}$ capacity, made of RCC, LLDPE and mild steel (stainless steel) was evaluated for life cycle analysis. The scope of the research comprised of the raw materials, energy inputs and corresponding emissions during all phases of product making such as extraction of raw material, it's processing, followed by manufacturing and transport, as well as use and reuse of the product. Simapro 8 (System for Integrated environMental Assessment of PROducts), a modelling software, from Dutch PRé Consultants was used to conduct the life cycle analysis. Simapro 8 enables systematic and transparent modelling and analysis of complex life cycles based on the recommendations of the ISO 14040 series of standards. In the present study the most common method which is acceptable worldwide "Recipe Endpoint method" (ReCiPe) was employed. ReCiPe computes the impact categories and classifies them into two classes based on relevant arrays of characterization factors. Simapro addresses impact categories viz. ozone depletion, human toxicity, ionizing radiation, photochemical oxidant formation, particulate matter formation, terrestrial acidification, climate change, terrestrial ecotoxicity, agricultural land occupation, urban land occupation, natural land transformation, marine ecotoxicity, marine eutrophication, fresh water eutrophication, fresh water ecotoxicity, fossil fuel depletion, minerals depletion, fresh water depletion at the midpoint level. While at the Endpoint level, the impact categories are multiplied by corresponding damage factors and integrated to be represented as three Endpoint level categories, viz. human health, ecosystems and resource depletion. The three endpoint categories are normalized, weighted, and aggregated into a single score. LCA studies indicate that household water tanks of LLDPE have least environmental implications considering impacts on human health, ecosystems and resource depletion as compared to its counterparts viz. Household water tanks made up of mild steel and RCC. The sequence of the material with decreasing impacts is concrete tanks > mild steel tank > LLDPE tanks. The overall assessment is centred on the elements such as material inputs, energy inputs and environmental emissions. 


\section{Keywords}

\section{Life Cycle Assessment, Water Tanks, Linear Low-Density Polyethylene (LLDPE), RCC, Mild Steel, Recipe Endpoint Method}

\section{Introduction}

Ensuring the availability of water for domestic requirements is indispensible in every household. Normally, in urban areas water is supplied to each house through network of pipelines and is stored in various ground-level and overhead water tanks. In the present study, considering the average daily requirement of a house, a $1000 \mathrm{~L}$ water tank is normally required to meet the requirements. At present this $1000 \mathrm{~L}$ water tank can be constructed using RCC, mild steel or polymer.

The environmental impacts of a product can be evaluated through life cycle assessment (LCA) which comprises of assessing the journey of a product right from the extraction of raw materials from the earth to the waste products being returned back to the earth. Life cycle assessment studies related to cement manufacturing [1], plastic manufacturing [2], different types of polymer used for container production [3] and several other studies have been conducted. To the best of our knowledge, no life cycle assessment of water tanks made from different materials has been done. This article deliberates upon the environmental impacts of domestic water tanks made of mild steel, RCC and LLDPE grounded on life cycle assessment (LCA) studies.

\section{Materials and Methods}

\subsection{Life Cycle Assessment (LCA)}

LCA, an environmental assessment tool, is a technique towards the evaluation of environmental impacts concomitant with all the stages of a product's life from cradle-to-grave (i.e. beginning from the extraction of raw material followed by materials processing, manufacture, distribution, use, repair, and maintenance, and disposal or recycling). The process of LCA enables the user to assemble an inventory of relevant energy and material inputs and environmental releases. The probable impacts associated with recognized inputs and releases can be evaluated. Interpretation of the results leads to make a more informed decision.

In agreement to the ISO 14040 and 14044 standards [4] [5], a LCA is conducted in four distinct phases' viz. Goal and Scope Definition; Inventory Analysis; Impact Assessment and Interpretation.

\subsection{Goal and Scope}

The goal of the study is to assess the potential life cycle environmental impacts of three different types of household water tanks and to compare between the three to conclude which tank is superior w.r.t. environmental aspect.

The goal of the study has been fragmented into the ensuing objectives:

a) To assemble a detailed life cycle inventory of the environmental burdens associated with the production, use and disposal of plastic (LLDPE), mild steel (stainless steel) and R.C.C tanks.

b) To use the life cycle inventory data to compare the environmental impacts arising from the three different types of tanks.

c) To equate the results of this study in identifying the "Environmental Hot Spots" and to suggest an improvements in the manufacturing process to overcome the environmental burdens.

The scope of the study includes the raw materials, energy inputs and corresponding emissions during all the phases of product making such as raw material extraction, processing, manufacturing, transport, use and reuse of the product.

\subsubsection{Functional Unit}

In order to conduct fair evaluation of results, the comparison of life cycle environmental impacts should be based on a comparable function (or "functional unit"). The water tanks studied are of different weights and qualities and are made up of different materials. The average water consumption of an individual is of 200 litres 
per capita per day (lpcd) and taking an average of five members in a family there is a requirement of 1000 lpcd. So, the functional unit is taken as $1000 \mathrm{~L}$ capacity water tank.

During the LCA methodology, modelling software SimaPro 8 (System for Integrated environMental Assessment of PROducts), from Dutch PRé Consultants (PRé, 2005) is employed for Life Cycle Inventory and Impact Assessment phases. Based on the recommendations of the ISO 14040 series of standards, Simapro allows to model and analyse complex life cycles in a systematic and transparent way.

\subsubsection{Foreground Data}

The foreground data as mentioned in Table 1 were used to generate the life cycle inventory for household water tanks made up of LLDPE, mild steel and RCC.

\subsection{Life Cycle Inventory Analysis}

The software considers three sorts of inputs. Inputs from nature, denotes inputs that are extracted from natural resources is the first type. It is noted that this refers to the fact that a resource is used; implicating the emissions and other environmental impacts to extract the resource should be included in the process. The second input type, inputs from technosphere (materials /fuel) denotes to materials and mass flows respectively supplied by other unit processes, whereas the third type, inputs from technosphere electricity/heat refers to non-mass flows including transport and energy supplied by other unit processes. It is emphasised that the only reason SimaPro separates mass and non-mass flows is to allow easier mass balance checks.

In reference to output for individual process, product and by-product outputs as well as waste to be sent to further treatment must be quantified. Moreover, data on five elementary output flows must be imported, viz. emissions to air, water and soil along with final waste flows and non-material emissions for instance noise. These elementary data together with inputs from nature will be used in inventory analysis of the product system.

The software internally computes through the "analyse" function, by employing a reduced matrix, calculates the system inventory by building the process trees and tracing all the references from one process record or product stage to another, thus integrating resource and emission substances as well as final waste flows per reference flow. The inventory result depicts all emissions and raw material consumption as a single list that is sorted alphabetically by substance name. These results can be split into the contributing processes. The objective is to understand the contribution of different product stages or processes to the total environmental load, as well as the contribution of raw materials and emissions.

\subsection{Life Cycle Impact Assessment}

The selection of the method depends on our goal in conducting the study; each and every method deals with the particular output like Carbon Footprint Assessment, Water footprint Assessment etc. In the present study the most common method which is worldwide acceptable "Recipe Endpoint method" is used.

Two sets of impact categories with accompanying sets of characterization factors are employed in ReCiPe method. At the midpoint level, 18 impact categories are addressed, viz. Ozone Depletion, Human Toxicity, Ionizing Radiation, Photochemical Oxidant Formation, Particulate Matter Formation, Terrestrial Acidification, Climate Change, Terrestrial Eco toxicity, Agricultural Land Occupation, Urban Land Occupation, Natural Land Transformation, Marine Eco Toxicity, Marine Eutrophication, Fresh Water Eutrophication, Fresh Water Eco Toxicity, Fossil Fuel Depletion, Minerals Depletion, Fresh Water Depletion.

Table 1. Foreground Data for construction/manufacturing of household water tanks.

\begin{tabular}{ccc}
\hline LLDPE Tanks & Stainless Steel (Mild steel) Tanks & R. C. C. (Cement Concrete) Tank \\
Mass of tank: $20 \mathrm{~kg}$ & Total mass : $140 \mathrm{~kg}$ & Amount of cement: $567 \mathrm{~kg}$ \\
Electricity required: $0.55 \mathrm{kWh} / \mathrm{kg}$ & Steel required: $138 \mathrm{~kg}$ & Amount of sand: $483 \mathrm{~kg}$ \\
Mould thickness: $2 \mathrm{~mm}$ & Transport: $28 \mathrm{~km}$. & Amount of coarse aggregates: $1019 \mathrm{~kg}$ \\
Life of tank: 25 years & Electricity: $8 \mathrm{kWh}$ & Amount of water: $0.093 \mathrm{~m}{ }^{3}$ \\
Recycling energy: $0.11 \mathrm{kWh} / \mathrm{kg}$ & Recyclability: $75 \%$ & Amount of Steel: $25 \mathrm{~kg}$ \\
LPG consumption: $0.125 \mathrm{~m}^{3} / \mathrm{kg}$ & Electricity during recycling: $7 \mathrm{kWh}$ & Electricity requirement: $10 \mathrm{kWh}$ \\
Time taken for production of tank: 5 min & Thickness of tank: $3 \mathrm{~mm}$ & Thickness of tank: $10 \mathrm{~cm}$ \\
\hline
\end{tabular}

$*$ tkm $=($ ton $\mathrm{x} \mathrm{km})$ is used for data to allocate road use to the service of goods transportation. 


\subsubsection{Ozone Depletion}

The destruction of the stratospheric ozone layer by anthropogenic emissions of ozone depleting substances (ODS) constitutes the characterization factor for ozone layer depletion. The unit is yr/kg CFC-11 equivalents.

\subsubsection{Human Toxicity and Eco Toxicity}

The environmental persistence (fate) and accumulation in the human food chain (exposure), and toxicity (effect) of a chemical comprises of the characterization factor of human toxicity and eco toxicity. The unit is $\mathrm{yr} / \mathrm{kg}$ 1,4-dichlorobenzene (14DCB).

\subsubsection{Radiation}

The level of exposure accounts as characterization factor of ionizing radiation. The unit is $\mathrm{yr} / \mathrm{kg}$ Uranium 235 equivalents.

\subsubsection{Photochemical Oxidant Formation}

The marginal change in the $24 \mathrm{~h}$-average European concentration of ozone ( $\mathrm{dCO} 3 \mathrm{in} \mathrm{kg} \cdot \mathrm{m}^{-3}$ ) due to a marginal change in emission of substance $\mathrm{x}\left(\mathrm{dMx}\right.$ in $\left.\mathrm{kg} \cdot \mathrm{year}^{-1}\right)$ is defined as the characterization factor of photochemical oxidant formation. The unit is $\mathrm{yr} / \mathrm{kg}$ NMVOC.

\subsubsection{Particulate Matter Formation}

The intake fraction of PM10 is the characterization factor of particulate matter formation. The unit is $\mathrm{yr} / \mathrm{kg}$ PM10 equivalents.

\subsubsection{Climate Change}

Global warming potential is the characterization factor of climate change. The unit is $\mathrm{yr} / \mathrm{kg} \mathrm{CO}_{2}$ equivalents

\subsubsection{Agricultural and Urban Land Occupation}

The amount of either agricultural land or urban land occupied for a certain time. The unit is $\mathrm{m}^{2} \cdot \mathrm{yr}$.

\subsubsection{Marine Eutrophication}

The environmental persistence (fate) of the emission of $\mathrm{N}$ containing nutrients is the characterization factor of marine eutrophication. The unit is $\mathrm{yr} / \mathrm{kg} \mathrm{N}$ to freshwater equivalents.

\subsubsection{Fresh water Eutrophication}

The environmental persistence (fate) of the emission of P containing nutrients is the characterization factor of freshwater eutrophication. The unit is $\mathrm{yr} / \mathrm{kg} \mathrm{P}$ to freshwater equivalents.

\subsubsection{Fossil fuel and Mineral Depletion}

The amount of extracted fossil fuel extracted based on the lower heating value is the characterization factor of fossil depletion. The unit is $\mathrm{kg}$ oil equivalent ( $1 \mathrm{~kg}$ of oil equivalent has a lower heating value of $42 \mathrm{MJ}$ ). The decrease in grade is the characterization factor for minerals depletion. The unit is kg Iron (Fe) equivalents.

\subsubsection{Damage Assessment}

The endpoint characterization factors used in ReCiPe can be termed as follows:

a) Human Health, expressed as the number of year life lost and the number of years lived disabled. These are combined as Disability Adjusted Life Years (DALYs), an index that is also used by the World Bank and WHO. The unit is years.

b) Ecosystems, expressed as the loss of species over a certain area, during a certain time. The unit is years.

c) Resources surplus costs, expressed as the surplus costs of future resource production over an infinitive timeframe (assuming constant annual production), considering a 3\% discount rate. The unit is 2000US\$.

The above sub categories are grouped into three major groups called Human health, Ecosystems and Resource depletion. These categories can be characterized, normalised, weighed and combined into single score results. By doing the analysis for each tank separately, the software generates the impact results. The results can be compared between three different tanks and conclusions can be made accordingly. The comparison between 
each phase of the particular tank along with the comparison of three different tanks was made.

At the Endpoint level most of the midpoint impact categories are multiplied by corresponding damage factors and combined into three Endpoint level categories, viz. Human Health, Eco systems and Resource Depletion. The three endpoint categories are normalized, weighted, and aggregated into a single score.

\section{Results and Discussion}

\subsection{Life Cycle Inventory Analysis}

\subsubsection{Plastic Tank (LLDPE) Network}

The plastic tank (LLDPE) network tree (Figure 1) exhibits the plastic tank raw material input composition in building the product. The thicker pathway shows the major material consumption (here polyethylene) and corresponding emissions or environmental impact during the production phase of material and also during the usage of material in the tank construction. The major impact in the production of plastic tank is by polyethylene occupying $82.2 \%$ followed by electricity requirement in the production phase $10.6 \%$ and fuel requirement through natural gas $6.11 \%$.

\subsubsection{Mild Steel Tank Network}

The mild steel network (Figure 2) shows the mild steel tank manufacturing tree starting from the raw material consumption. The major impact on the environment is due to the consumption of steel as the majority of emissions are released during the extraction and processing of steel from its ore. The impact was measured as $97.8 \%$ followed by electricity in manufacturing and transportation of raw material to factory and also shipping of finished product to the consumer using road transport. The transportation and electricity together constitutes remaining percentage. The network also shows the electricity generation from the coal.

\subsubsection{RCC Tank Network}

The RCC tank network (Figure 3) shows the manufacturing of R.C.C tank or cement concrete tank. Here as the reinforcement is provided during the tank construction, the amount of steel required is being calculated by using foreground data. The impact from the cement preparation and usage in the construction of tank stands first with $53.1 \%$ followed by steel for reinforcement with $38.3 \%$. As the material requirement for the tank construction are relatively higher compared to that of plastic and mild steel tanks the emissions due to transportation of raw materials to the site are also higher and the impact due to transport higher compared to that of plastic and mild steel tanks and stood at $3.74 \%$.

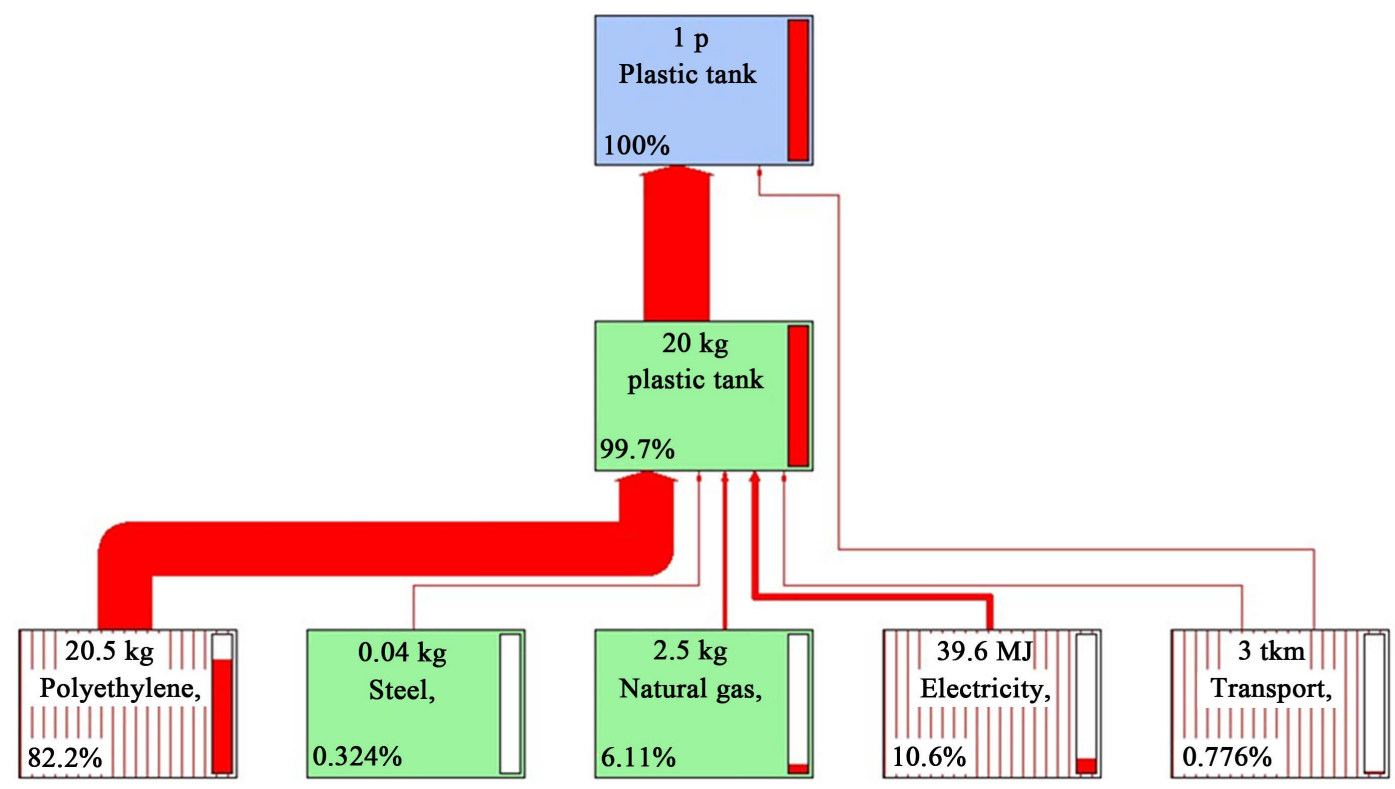

Figure 1. Network showing LLDPE tank manufacturing tree. 


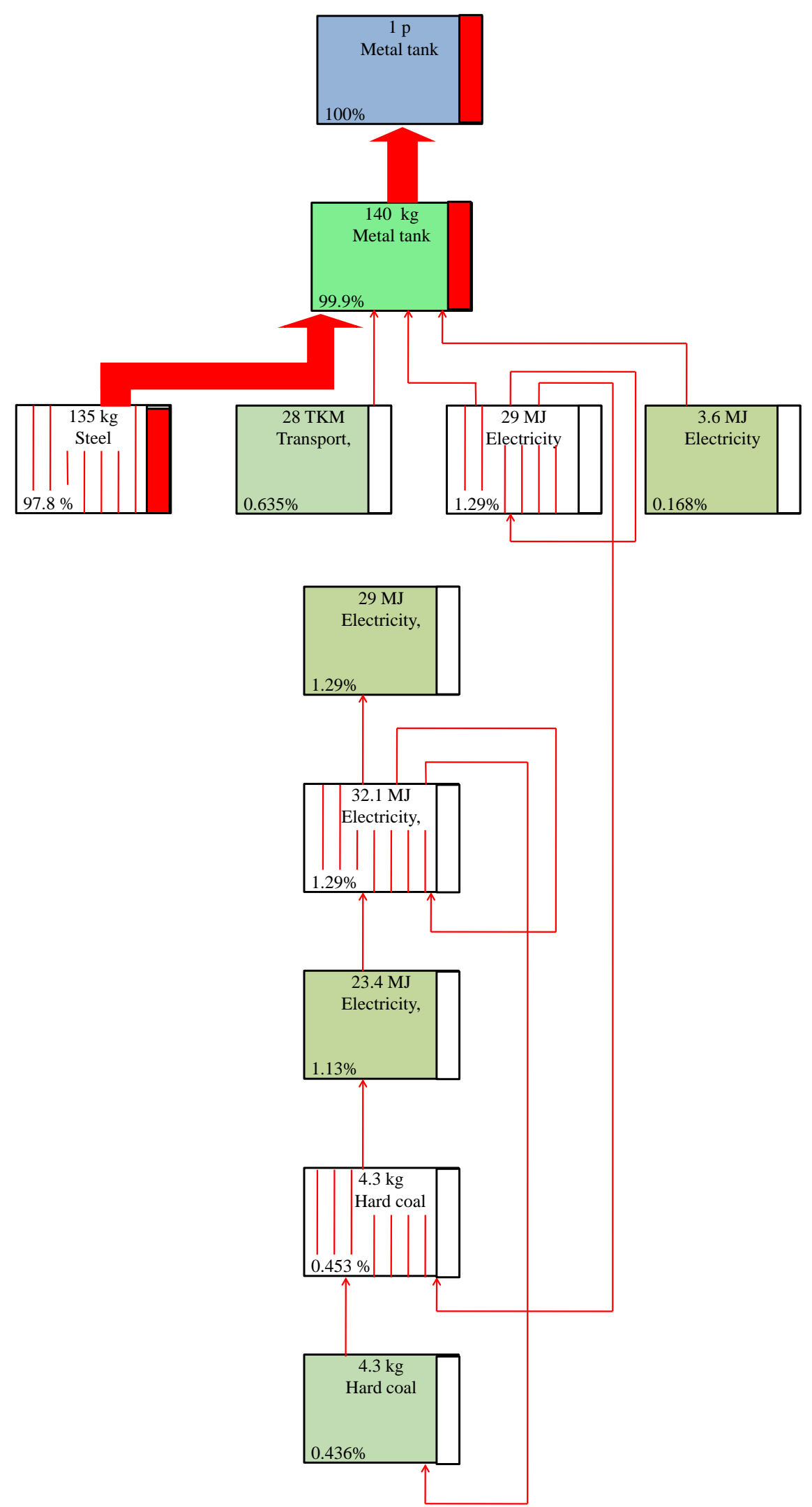

Figure 2. Network showing mild steel tank manufacturing tree. 


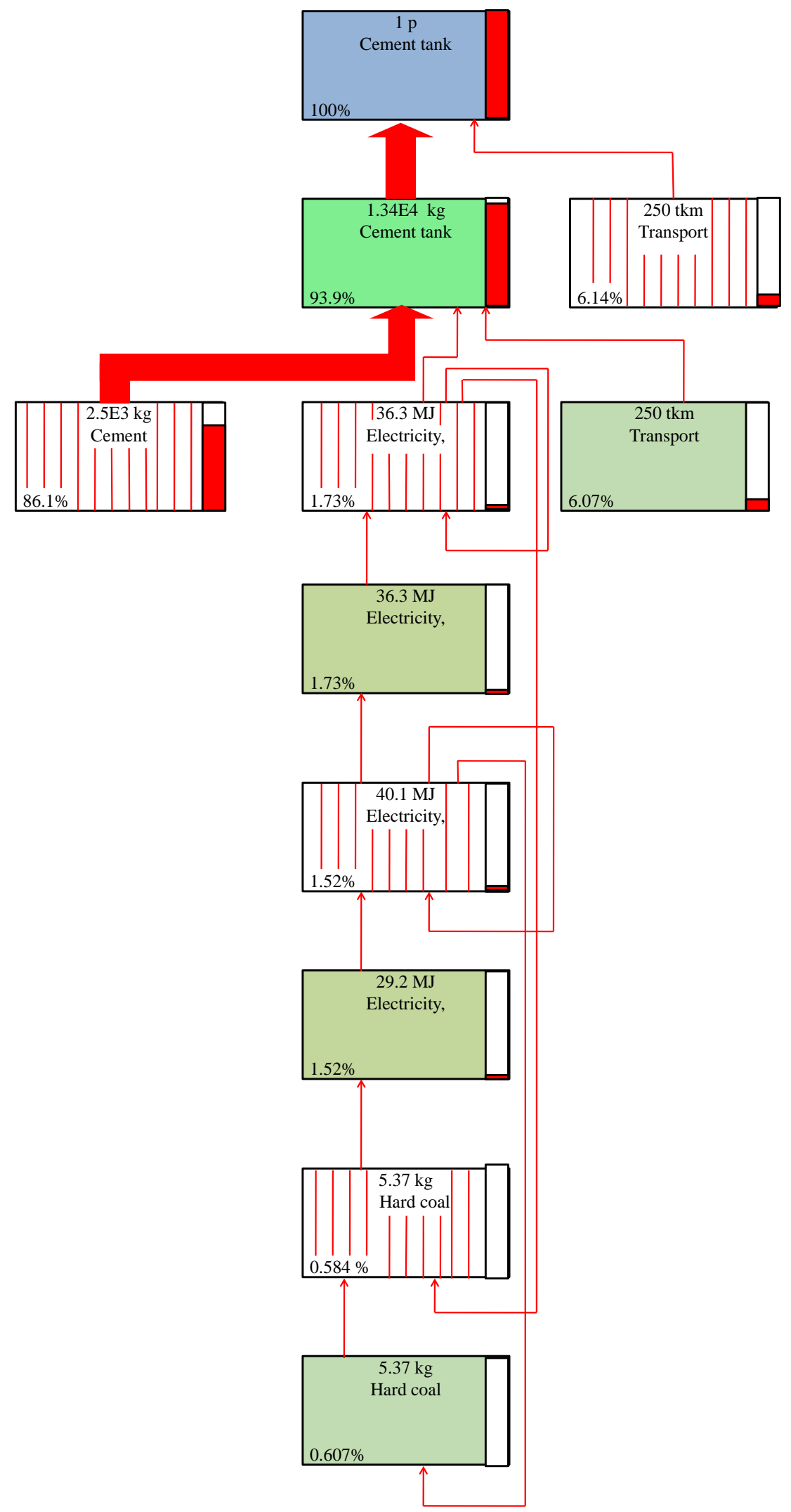

Figure 3. Network showing RCC tank manufacturing tree. 


\subsection{Life Cycle Assessment}

\subsubsection{Damage Assessment of Plastic Tank (LLDPE)}

The damage assessment of different phases of LLDPE tank on three categories namely Human Health, Ecosystems and Resources is exhibited in Figure 4. The impact of plastic tank life cycle is less compared to plastic tank as there is very high recyclability of tank thereby no further resource depletion at the end of life. The results shows that life cycle of plastic tank has $48 \%, 45 \%$, 24\% impact on human health, ecosystems and resource depletion respectively compared to plastic tank which is taken as $100 \%$. The disposal scenario is shown as negative as it has no impact on environment due to negligible resource depletion.

\subsubsection{Damage Assessment of Mild Steel Tank}

The damage assessment results of mild steel tank on human health, ecosystems and resource depletion is demonstrated in Figure 5. The results are similar to plastic tank but the values are comparatively lower as the production phases are not energy intensive. The results shows that the life cycle of tank has $28 \%$, 28\% and 25\% impact on the human health, ecosystems and resources respectively compared to mild steel tank use phase which is taken as $100 \%$. The negative phase of the results shows that the disposal scenario includes recycling phase and hence those impacts can be subtracted from mild steel tank to get life cycle impacts.

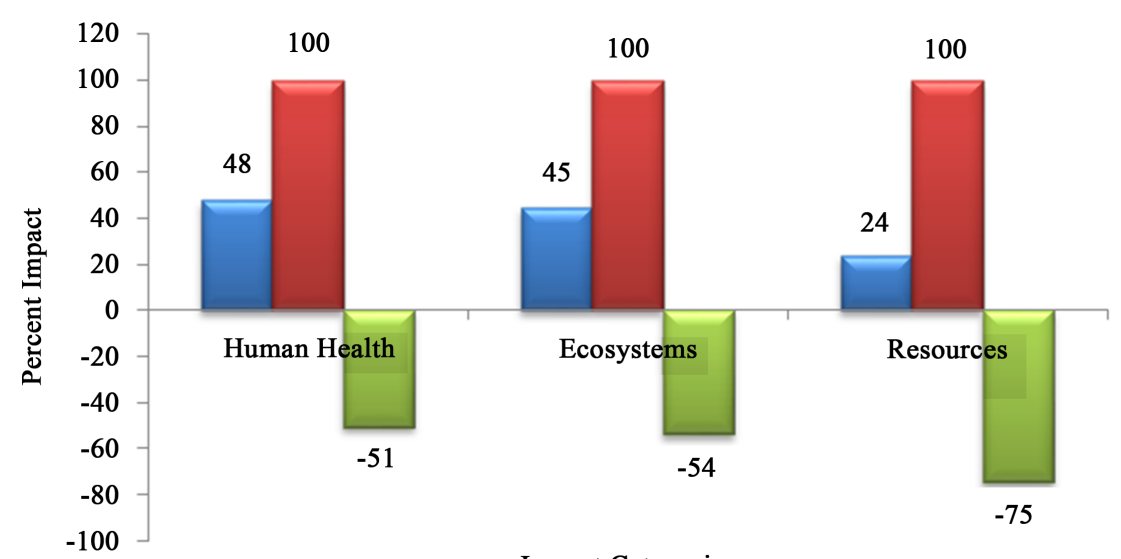

Impact Categories

$\square$ Plastic Tank Life Cycle $\quad \square$ Plastic Tank $\quad \square$ Plastic Tank Disposal Scenario

Figure 4. Damage assessment of LLDPE tank.

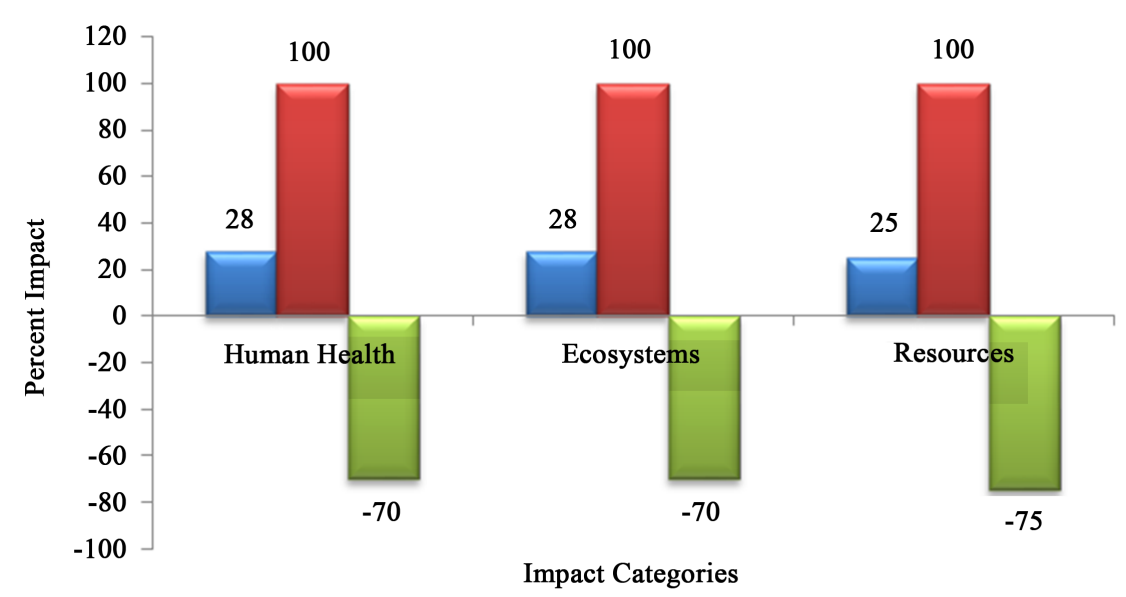

$\square$ Metal Tank Life Cycle $\square$ Metal Tank $\square$ Metal Tank Disposal Scenario

Figure 5. Damage assessment of mild steel tank. 


\subsubsection{Damage Assessment of RCC Tank}

Figure 6 depicts the impacts of concrete tank vary from that of plastic and mild steel tanks, especially during disposal scenario. As concrete after dismantling cannot be recycled there is no subtraction of impacts from use phase of tank but in fact it is the addition. The impacts of tank are compared with the life cycle phase which is taken as $100 \%$. Concrete tank has $88 \%, 86 \%$ and $87 \%$ impacts as compared to its life cycle on human health, ecosystems and resources.

\subsubsection{Comparative Damage Assessment of RCC, Mild Steel and LLDPE Tanks}

As observed in Figure 7 the impact of RCC tank on human health, ecosystems and resources is taken as 100\% and the relative impact of mild steel and LLDPE tanks on the three parameters have been computed. It is observed that mild steel tank affects human health, ecosystems and resources by $39 \%$, $29 \%$ and $61 \%$, while the LLDPE's impact is observed to be around 5\% on all three parameters. Overall, assessment shows that LLDPE tanks have lowest impact compared to their counterparts, mild steel and RCC tanks on human health, ecosystems and resources.

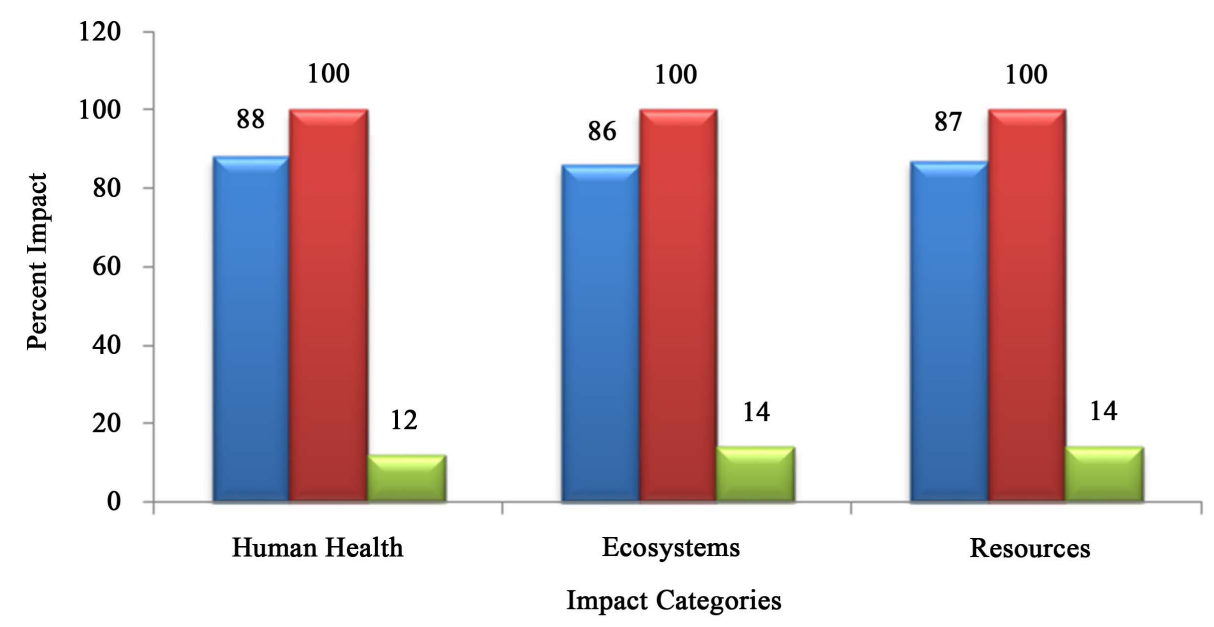

$\square$ RCC Tank Life Cycle $\quad \square$ RCC Tank $\square$ RCC Tank Disposal Scenario

Figure 6. Damage assessment results of RCC tank.

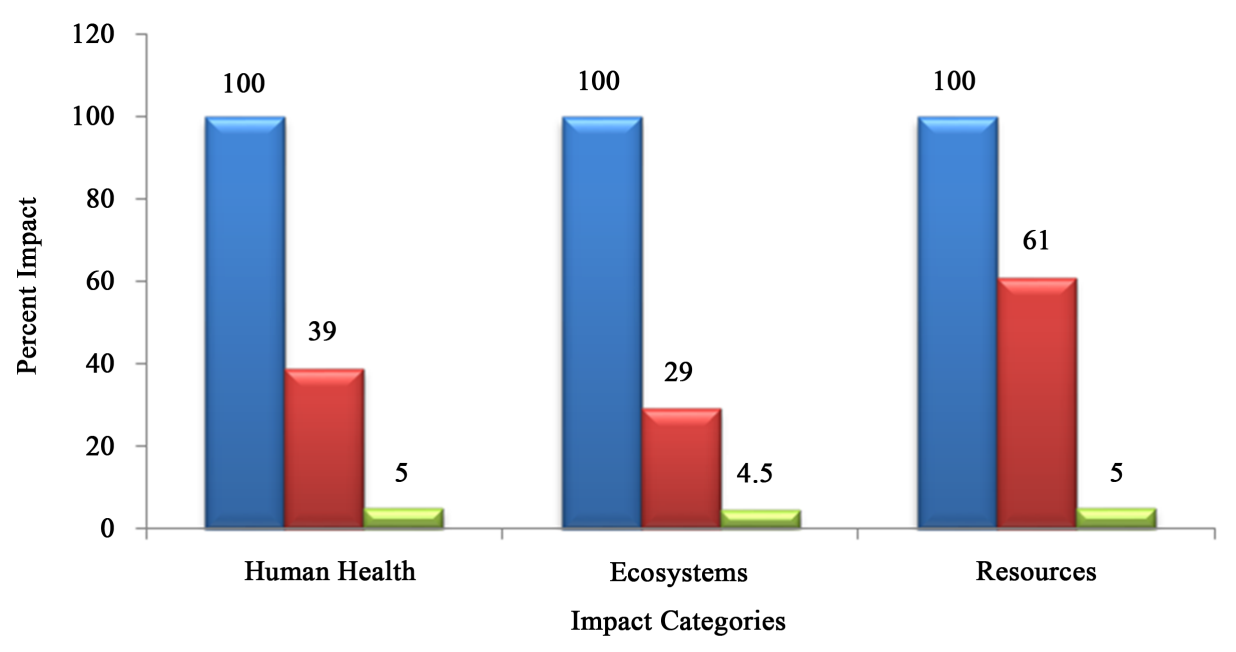

$\square$ RCC Tank Life Cycle $\square$ Metal Tank Life Cycle $\square$ Plastic Tank Life Cycle

Figure 7. Comparative damage assessment of RCC, Mild steel and LLDPE tanks. 
In the current study it is observed that during the manufacturing of LLDPE tanks, major impact is by polyethylene, while during the production of mild steel tank, steel has major impact. On examination of the construction of RCC tank, cement and steel have major impact. During damage assessment, it is observed that due to high recyclability of LLDPE, it has least impact on human health, ecosystems and resources. While in case of damage assessment for mild steel tanks, the corrosion losses are added which reduces the steel availability for recyclability, thereby its comparative impact is less than RCC tanks, but more than LLDPE tanks. On considering the damage assessment for RCC tank, the disposal involves dumping to the earth; thereby almost nothing is available for recycling which makes highest impact during damage assessment.

In nutshell, the life cycle assessment of household water tank reveals that LLDPE make water tanks contribute to least damage on human health, ecosystems and resource depletion compared to its counterparts, mild steel and RCC tanks.

\section{Conclusions}

Based on the foregoing discussion following conclusions have been drawn:

1) LCA studies indicate that household water tanks of LLDPE have least environmental implications considering impacts on human health, ecosystems and resource depletion as compared to its counterparts viz. household water tanks made up of mild steel and RCC.

2) The sequence of the material with decreasing impacts is concrete tanks > mild steel tank > LLDPE tanks.

3) The scope of the study included the raw materials, energy inputs and corresponding emissions during all phases of product making such as raw material extraction, processing, manufacturing, transport, use and reuse of the product.

4) The LCA results have been obtained through SimaPro software by using Recipe Endpoint method which considers 18 parameters as discussed in Section 2.4.

Such studies can lead to public awareness of environmental issues which can lead as trails for industry and business to design and develop more ecological products and to inform stakeholders on by what means their activities produce emissions and consume natural resources.

\section{Acknowledgements}

The authors are thankful to Mr. Prashant Trivedi of Sintex Industries Ltd., Gujarat, for technical discussions. KS is thankful to Mr. Sanjeev Yendamuri for interactions related to software. The authors are grateful to Prof. T. Harinarayana, Director, Gujarat Energy Research and Management Institute (GERMI) for constant encouragement and support.

\section{References}

[1] Zhang, J., Liu, G., Chen, B., Song, D., Qi, J. and Liu, X. (2014) Analysis of $\mathrm{CO}_{2}$ Emission for the Cement Manufacturing with Alternative Raw Materials: A LCA-Based Framework. Energy Procedia, 61, 2541-2545. http://dx.doi.org/10.1016/j.egypro.2014.12.041

[2] Dormer, A., Finn, D., Ward, P. and Cullen, J. (2013) Carbon Footprint Analysis in Plastics Manufacturing. Journal of Cleaner Production, 51, 133-141. http://dx.doi.org/10.1016/j.jclepro.2013.01.014

[3] Madival, S., Auras, R., Singh, S. and Narayan, R. (2009) Assessment of the Environmental Profile of PLA, PET and PS Clamshell Containers Using LCA Methodology. Journal of Cleaner Production, 17, 1183-1194. http://dx.doi.org/10.1016/j.jclepro.2009.03.015

[4] ISO International Organization for Standardization (2006) Environmental Management-Life Cycle AssessmentPrinciples and Framework. ISO 14040:2006(E), Geneva.

[5] ISO International Organization for Standardization (2006) Environmental Management—Life Cycle AssessmentRequirements and Guidelines. ISO 14044:2006(E), Geneva. 